\title{
EFEITOS DE CHOQUES TÉRMICOS NA GERMINAÇÃO DE PAEPALANTHUS SPECIOSUS KOERN. (ERIOCAULACEAE)
}

\author{
C. G. Sá e Carvalho' \\ M. C. Ribeiro ${ }^{2}$
}

Recebido em 16.9.91. Aceito em 14.7.94

\begin{abstract}
RESUMO - (Efeitos de choques térmicos na germinação de Paepalanthus speciosus Koern. Eriocaulaceae). Sementes de Paepalanthus speciosus Koern. - Eriocaulaceae, contidas em frutos nus e no diásporo, apresentaram tolerância a choques térmicos de até $70^{\circ} \mathrm{C}$ por 30 minutos e essa capacidade não foi modificada quando as temperaturas foram fornecidas após 24 horas de embebição. Observou-se também que o fotoblastismo das sementes não foi alterado por tratamento com temperaturas de 35 a $80^{\circ} \mathrm{C}$ durante 30 minutos. Os resultados obtidos mostram que sementes de $P$. speciosus possuem elevada capacidade de sobrevivência à temperatura atingida durante as queimadas que ocorrem anualmente nos campos cerrados.
\end{abstract}

Palavras-chave - Paepalanthus speciosus, Eriocaulaceae, germinação, fotoblastismo, campo rupestre.

\begin{abstract}
Effects of thermic shocks in the germination of Paepalanthus speciosus Koern. Eriocaulaceae). Seeds of Paepalanthus speciosus Koern. - Eriocaulaceae, when enclosed into naked fruits and in the diaspores, showed tolerance at thermic shock until $70^{\circ} \mathrm{C}$ during $30 \mathrm{~min}$. and this capacity was not modified when the thermic shock happened $24 \mathrm{~h}$ after the imbebition. Seed photoblastism was not affected by treatment with temperatures from 35 to $80^{\circ} \mathrm{C}$ during $30 \mathrm{~min}$. These results showed that seeds of $P$. speciosus have high capacity of survival at temperature developed during the burn of annual occurrence on "campo rupestre".
\end{abstract}

Key words - Paepalanthus speciosus, Eriocaulaceae, germination, photoblastism, "campo rupestre".

\section{Introdução}

Os campos rupestres brasileiros apresentam vegetação rica e variada e, nas últimas décadas, algumas espécies conhecidas como "sempre vivas" têm sido coletadas de maneira indiscriminada e exportadas com a finalidade de serem utilizadas na ornamentação de interiores (Giulietti et al. 1988). A coleta indiscriminada e as

\footnotetext{
' Departamento de Botânica - ICB - UFG. 74.000, Goiânia-GO. Bolsista do CNPq.

2 Escola de Agrônomia da UFG. Bolsista de Iniciação Científica do CNPq.
} 
frequentes queimadas que ocorrem na época seca do ano tornam as "sempre vivas" factíveis de desaparecimento.

Embora já tenham sido realizados estudos sobre o efeito ecológico do fogo em vegetação do cerrado (Coutinho 1978a, 1978b, 1979, 1980, Coutinho et al. 1982), pouco se sabe da germinação de sementes que ocorrem nesse habitat, quando submetidas às temperaturas das queimadas.

Este trabalho teve por objetivo verificar o efeito de choques térmicos na germinação de sementes de Paepalanthus speciosus, uma "sempre viva"que ocorre em campo rupestre da Serra Dourada no Estado de Goiás. As sementes dessa espécie são fotoblásticas positivas e apresentam elevada viabilidade.

\section{Material e métodos}

Inflorescências de Paepalanthus speciosus Koern. foram coletadas em agosto de 1988 na Reserva Biológica da Serra Dourada, município de Mossâmedes - Estado de Goiás, amarzenadas em sacos de vidro âmbar e mantidas sob condiçãoambiente.

Nos testes de germinação foram utilizados frutos nus e diásporos, uma vez que a remoção das sementes mostrou-se inviável.

Os testes de germinação foram realizados em placas de Petri de $9 \mathrm{~cm}$ dediâmetro, estéreis, contendo dois discos de papel de filtro com $5 \mathrm{ml}$ de água destilada. Cada tratamento constou de cinco repetições de 20 , ou 30 frutos e todos os testes foram conduzidos sob luz e escuro constantes e temperatura ambiente.

A condição de escuro foi obtida envolvendo-se cada placa em dois sacos plásticos pretos e a luz foi fornecida por quatro lâmpadas fluorescentes de 40 watts cada, dispostas a $170 \mathrm{~cm}$ de distância. A verificação da germinação sob condição de escuro constante foi realizada sob luz verde de segurança e a contagem do número de frutos germinados foi efetuada sob microscópio estereoscópico.

Frutos nus e diáporos foram submetidos a choques térmicos de 35, 40, 50, 60, 70 e $80^{\circ} \mathrm{C}$ durante $30 \mathrm{~min}$, em estufas FANEM com temperatura controlada, antes e após 24 horas de embebição.

Os frutos submetidos aos diferentes choques térmicos e mantidos sob escuro constante por 40 dias sem apresentaram germinação, foram transferidos para condição de luz constante determinando-se o efeito do longo período de hidratação na germinação das sementes.

O delineamento experimental foi o de casualização completa e os resultados obtidos foram transformados em valores angulares (arco seno $\sqrt{\%}$ ) e submetidos à análise de variância (Teste de F). As comparações entre as médias foram realizadas mediante a aplicação do teste de Tukey ao nível de 5\% de probabilidade. Foram determinados, para cada parâmetro estudado, os coeficientes de variabilidade (Gomes, 1985). 


\section{Resultados e discussão}

A Figura 1 mostra que choques térmicos de $40,50,60$ e $70^{\circ} \mathrm{C}$ fornecidos antes da embebição não afetaram a germinação e o fotoblastismo das sementes de Paepalanthus speciosus contidas em frutos nus. $\mathrm{O}$ mesmo foi observado quando diásporos foram submetidos a choques térmicos de até $80^{\circ} \mathrm{C}$ por min. (Figura 2).

Alguns trabalhos têm mostrado que o fotoblastismo pode ser afetado pela temperatura. Isikawa \& Fujii (1961) observaram que sementes de Rumex spp., que apresentavam baixa porcentagem de germinação no escuro, germinaram bem quando foram tratadas com temperatura elevada por um curto período de tempo. Felippe et al (1971), mostraram que choques de temperatura de 34 a $42^{\circ} \mathrm{C}$ promoviam a germinação de aquênios de Porophyllum lanceolatum mantidos no escuro a $25^{\circ} \mathrm{C}$. As Figuras 1, 2, 3 , e 5 mostram que o fotoblastismo de sementes de $P$. speciosus não é modificado por choques de temperatura de 35 a $80^{\circ} \mathrm{C}$ durante $30 \mathrm{~min}$.

Sementes de Paepalanthus speciosus contidas em frutos nus e embebidas durante 24 horas antes dos tratamentos com choques térmicos de até $70^{\circ} \mathrm{C}$ durante 30 min., apresentaram porcentagens de germinação que não diferiram significantemente daquele fornecido pela testemunha (Figura 3). As sementes submetidas a choques térmicos e mantidas sob escuro constante durante 40 dias sem apresentarem germinação, quando removidas para condição de luz constante, atingiram máxima porcentagem de germinação após 14 dias, como mostra Figura 4. Observa-se também que os choques térmicos de até $70^{\circ} \mathrm{C}$ não afetaram esse processo. Comparando os resultados apresentados na Figura 4 com os da Figura 3, observa-se que a permanência de frutos nus de $P$. speciosus em condição de hidratação e no escuro por 40 dias, provocou a diminuição do período germinativo após exposição à luz. Esses resultados mostram que o fitocromo não foi afetado nem pelas elevadas temperaturas, fornecidas após a embebição das sementes, nem pelo longo período de hidratação sem incidência de luz. A diminuição do período germinativo observado em sementes hidratadas por 40 dias (Figura 4) pode ser devido a alguma alteração no fitocromo propiciando maior eficiência em sua conversão para a forma ativa (FVe) quando da incidência de luz, e manifestada pelo aumento na velocidade de germinação.

A Figura 5 mostra que a embebição de diásporos de $P$. speciosus por 24 horas antes de serem submetidos a choques térmicos de 40 e $50^{\circ} \mathrm{C}$ não afetou a germinação e o fotoblastismo das sementes. Esses resultados confirmam aqueles observados quando frutos nus, pré-embebidos, foram submetidos à temperatura de até $70^{\circ} \mathrm{C}$ por 30 min. (Figura 3).

Poucos são os trabalhos sobre o efeito de choques térmicos em sementes de plantas ocorrentes em cerrado. Rizzini (1976), estudando 28 espécies de cerrado, observou que temperatura de $80^{\circ} \mathrm{C}$ durante cinco minutos apresenta pequena influência em sua germinação e dentre 40 espécies savanícolas estudadas, somente Magonia pubescens e Bowdichia major apresentaram algum benefício na germinação, quando suas sementes foram submetidas a tratamento de $100^{\circ} \mathrm{C}$ por min. Dionello (1979) observou que das sementes de Kilmeyera coriacea, submetidas a choques térmicos 


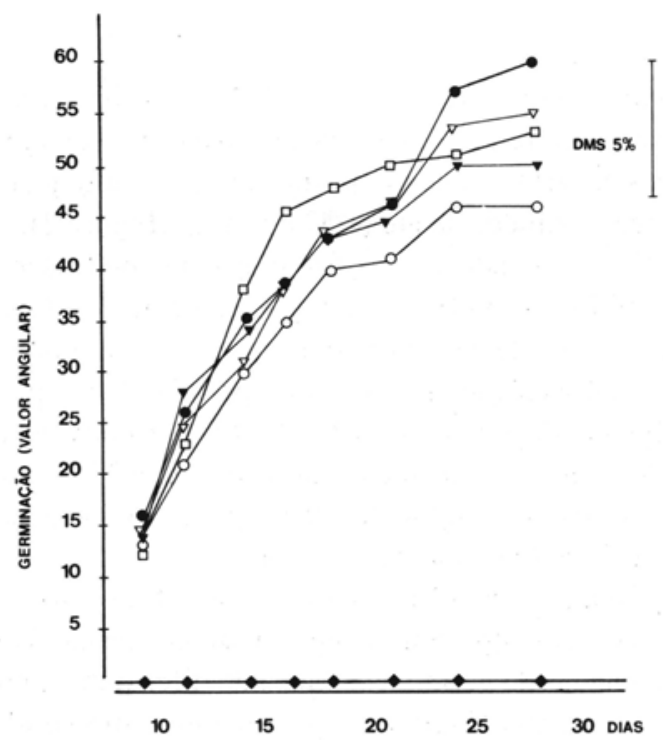

FIGURA 1- Germinação de frutos nus de Paepalanthus speciosus Koern. submetidos a choques térmicos. Sob luz constante: $\square$ testemunha, $\nabla 40^{\circ} \mathrm{C} \bullet 50^{\circ} \mathrm{C} O 60^{\circ} \mathrm{C} \nabla 70^{\circ} \mathrm{C}$. Sob escuro constante: testemunha, $40,50,60.70^{\circ} \mathrm{C}$ c.v. $=14,39$

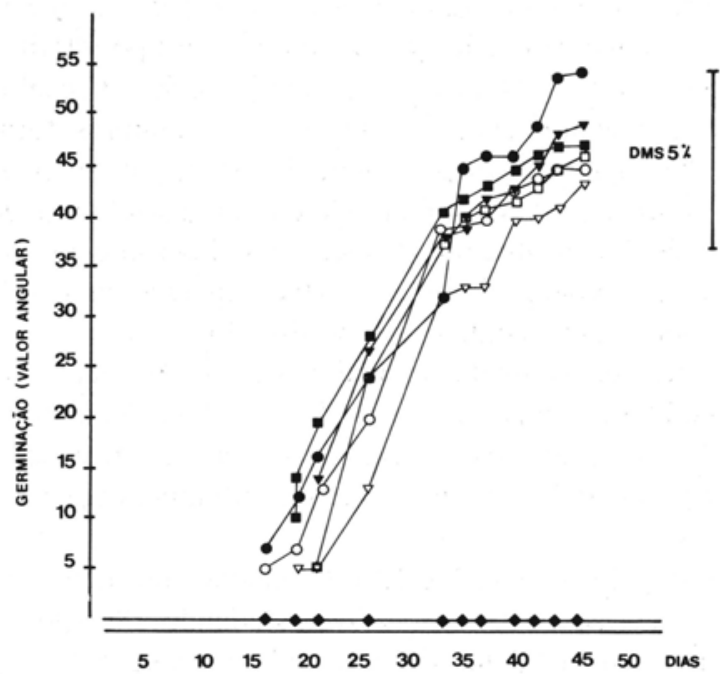

FIGURA 2- Efeito de choques térmicos na germinação de diásporos de Paepalanthus speciosus Koern. Sob luz constante: $\bullet$ testemunha, $\square 40^{\circ} \mathrm{C}, \boldsymbol{\nabla} 50^{\circ} \mathrm{C}, \nabla 60^{\circ} \mathrm{C}, \boldsymbol{m} 70^{\circ} \mathrm{C}, \mathrm{O} 80^{\circ} \mathrm{C}$. Sob constante: $\downarrow$ testemunha, $40,50,60,70,80^{\circ} \mathrm{C} . \mathrm{CV}=19,29$. 


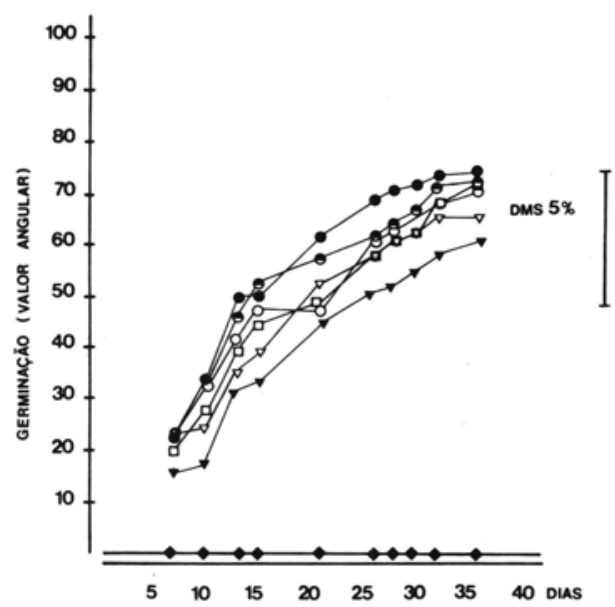

FIGURA 3- Germinação de frutos nus de Paepalanthus speciosus Koern. pré-embebidos e submetidos a choques térmicos. Sob luz constante: $\bullet$ testemunha, $\square 35^{\circ} \mathrm{C}, \bullet 40^{\circ} \mathrm{C}, \nabla 50^{\circ} \mathrm{C}, \mathrm{O} 60^{\circ} \mathrm{C}, \boldsymbol{\nabla} 70^{\circ} \mathrm{C}$. Sob escuro constante: $\downarrow$ testemunha, $35,40,50,60,70^{\circ} \mathrm{C} . \mathrm{CV}=9,81$.

variáveis de 50 a $100^{\circ} \mathrm{C}$ durante 5,10 e $15 \mathrm{~min}$, somente não germinaram aquelas tratadas com choques de $100^{\circ} \mathrm{C}$. Joly et al. (1980) verificaram que sementes intactas de Magonia pubescens, quando submetidas a choques de $45^{\circ} \mathrm{C}$ por um período de 72 horas, apresentaram inibição da germinação. Carvalho \& Cruvinel (1991), observaram que choques térmicos de até $80^{\circ} \mathrm{C}$ por $30 \mathrm{~min}$., fornecidos antes da embebição das sementes, não danificaram a capacidade de germinação de Dyckia sp., espécie ocorrente em campo rupestre, enquanto que, em sementes pré-embebidas por 24 horas, temperaturas de 70 e $80^{\circ} \mathrm{C}$ por $30 \mathrm{~min}$ afetaram significantemente sua germinação.

Sementes de Paepalanthus speciosus apresentaram tolerância a choques térmicos de até $80^{\circ} \mathrm{C}$ por $30 \mathrm{~min}$, quando contidas em frutos nus e em diásporos (Figuras 1 e 2) e essa capacidade não se modificou quando os choques térmicos foram fornecidos após 24 horas de embebição (Figuras 3 e 5), sugerindo elevada capacidade de sobrevivência à temperatura atingida durante as queimadas que, segundo Coutinho (1978b), alcança valor máximo de $74^{\circ} \mathrm{C}$ à superfície do solo, durante alguns minutos, em uma formação de campo cerrado da região de Emas (São Paulo). 


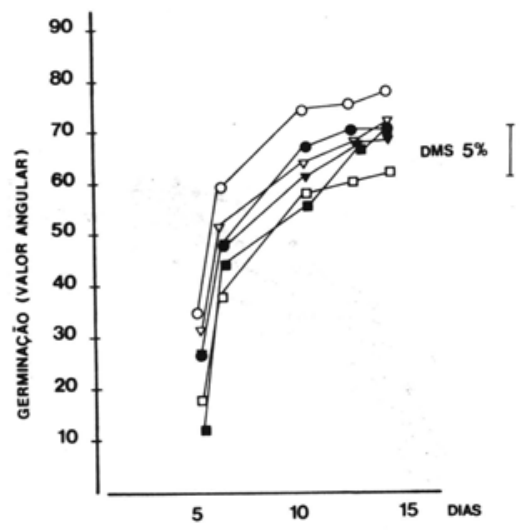

FIGURA 4- Germinação de frutos nus de Paepalanthus speciosus Koern. submetidos a choques térmicos, após 40 dias de hidratação no escuro e remoção para condição de luz constante. $\bullet$ testemunha, $\nabla 35^{\circ} \mathrm{C}$, $\mathrm{O} 40^{\circ} \mathrm{C}, \boldsymbol{\nabla} 50^{\circ} \mathrm{C}, 60^{\circ} \mathrm{C}, \square 70^{\circ} \mathrm{C} . \mathrm{CV}=9,47$.

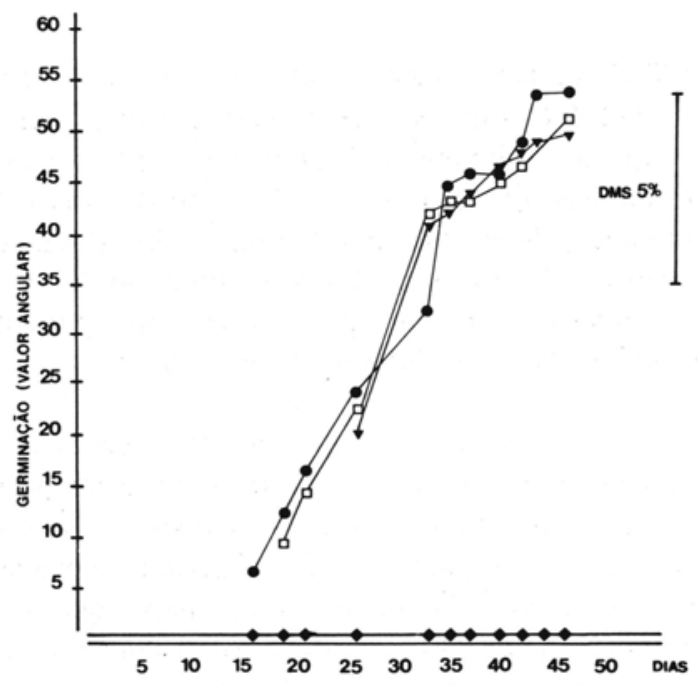

FIGURA 5 - Efeito de choques térmicos na germinação de diásporos pré-embebidos de Paepalanthus speciosus Koern. Sob luz constante: $\bullet$ testemunha, $\square 40^{\circ} \mathrm{C}, \boldsymbol{\nabla} 50^{\circ} \mathrm{C}$. Sob escuro constante: $\bullet$ testemunha, $40^{\circ} \mathrm{C}, 50^{\circ} \mathrm{C} . \mathrm{CV}=6,0$. 


\section{Referências bibliográficas}

Coutinho, L.M. 1978a. O conceito de cerrado. Revta bras. Bot. 1:17-23.

Coutinho, L.M. 1978b. Aspectos ecológicos do fogo no cerrado. I - A temperatura do solo durante as queimadas. Revta bras.Bot. 1:93-96.

Coutinho, L.M. 1979. Aspectos ecológicos do fogo no cerrado. III - A precipitação atmosférica de nutrientes mineirais. Revta bras.Bot. 2:97-101.

Coutinho, L.M. 1980. As queimadas e seu papel ecológico. Brasil Florestal 44:7-23.

Coutinho, L.M., Vuono,Y.S., de Sousa, J.S. 1982. Aspectos ecológicos do fogo no cerrado. IV - A época da queimada e a produtividade primária líquida epigéia do extrato herbáceo sub-arbustivo. Revta bras.Bot. 5:37-41.

Dionello, S.B. 1979. Efeito do choque térmico sobre a germinação de Kilmeyera coriaceae Mart. Ciência \& Cultura 31 (Supl.) p. 675.

Felippe, G.M., Giulietti, A.M. \& Lucas, N.M.C. 1971. Estudos de germinação de Porophyllum lanceolatum DC. I- Efeito de luz, temperatura e fotoperíodo. Hoehnea 1:1-9.

Gomes, F.P. 1985. Curso de Estatística Experimental, São Paulo: Livraria Nobel.

Isikawa, S. \& Fujii, T. 1961. Photocontrol and temperature dependence of germination of Rumex species. Plant \& Cell Physiol. 2:51-62.

Joly, C.A., Felippe, G.M., Dietrich, S.M.C. \& Campos -Takaki, G.M. 1980. Physiology of germination and seed gel analysis in two populations of Magonia pubescens St.Hil. Revta bras. Bot. 3:1-9.

Giulietti,N., Giulietti, A.M., Pirani, J.R. \& Menezes, N. L. 1986. Estudos em sempre-vivas: importância econômica do extrativismo em Minas Gerais, Brasil. Acta bot. bras. 1(2): 179-193. supl.

Rizzini, C.T. 1976. Influência da temperatura sobre a germinação de diásporos de cerrado. Rodriguésia 41:341-383. 